\title{
EMR modelling of a hydrogen-based electrical energy storage.
}

\author{
K. S. AGBLI ${ }^{1,2, a}$, D. HISSEL ${ }^{1, b}$, M-C. PERA ${ }^{1, c}$, and I. DOUMBIA ${ }^{2, d}$ \\ 1 University of Franche-Comte, Femto-ST UMR 6174, FC LAB Institute, 90016 Belfort, cedex France \\ 2 Signals and Systems laboratory, University of Cocody-Abidjan, 01 BP V34 Abidjan 01, Ivory Coast
}

the date of receipt and acceptance should be inserted later

\begin{abstract}
Résumé This paper deals with multi-physics modelling of the stationary system. This modelling is the first step to reach the fuel cell system dimensioning aim pursued. Besides this modelling approach based on the stationary energetic system, the novelty in this paper is both the new approach of the photovoltaic EMR modelling and the EMR of the hydrogen storage process. The granular modelling approach is used to model each component of the system. Considering a stand alone PEM fuel cell system, hydrogen is expected to be produced and stored on the spot from renewable energy (photovoltaic) in order to satisfy the fuel availability. In fact, to develop a generic and modular model, Energetic Macroscopic Representation (EMR) is used as graphical modelling tool. Allowing to be easily grasped by the experts even not necessarily gotten used to the modelling formalism, EMR is helpful to model the multi-domains energetic chain. The solar energy through solar module is converted in electrical energy ; part of this energy is transformed in chemical energy (hydrogen) thanks to an electrolyser. Then the hydrogen is compressed into a tank across a storage system. The latter part of the solar module energy is stored as electrical energy within supercapacitor or lead-acid battery. Using the modularity feature of the EMR, the whole system is modelled entity by entity; afterwards by putting them together the overall system has been reconstructed. According to the scale effect of the system entities, some simulation and/or experimental results are given. Given to the different aims which are pursued in the sustainable energy framework like prediction, control and optimisation, EMR modelling approach is a reliable option for the energy management in real time of energetic system in macroscopic point of view.
\end{abstract}

\section{Introduction}

Facing the rarefaction of fossil fuels and reducting the green-house effect linked to gas emissions, are interesting scientific and technological challenges for the next years. To face these challenges, scientific research for production and exploitation of energy addresses the reduction of energy consumption and the production from sustainable energy. The solar energy is one of the possible primary sources. Due to the night and day intermittency, a system involving energy vectors as hydrogen and electricity can be designed to build an efficient, clean and reliable energy generator. Basic components in such a system are photovoltaic cell, electrolyser, gas storage, fuel cell.

New material and new component development can bring the expected breakthrough. In order to improve the performances of the photovoltaic cells, new technologies are in development as organic cells [1] [2] [3], heterojunctionl cells [4] [5], semi-transparent and semi-permeable films [6] [7] and the multilayer thin film technology [8]. New methods of solidification are used to optimize the

Correspondence to: ${ }^{a}$ serge.agbli@femto-st.fr

,$b$ daniel.hissel@univ-fcomte.fr

${ }^{, c}$ marie-cecile.pera@univ-fcomte.fr

${ }^{, d}$ issadoum@yahoo.fr cell efficiency [9]. Proton exchange polymers are the key components of the low temperature technology for fuel cell and electrolyser, new process are in development as the synthesis of solid polymer fuel cell by low pressure plasmas [10] [11].

The components are integrated in a production system to reach the energy needs and respect the constraints of the application, mobile and stationary as well. Then, besides the performances of the components by themselves, the architecture and the sizing of the system including power converters and auxiliaries require a global approach. Graphical methods are then of main interest for an efficient design and exploitation of energy supply devices.

In this article, a local clean grid for domestic application is considered. The energy conversion chain is presented : the photovoltaic energy can supply directly the load and/or be converted in chemical energy through an electrolyser which produce hydrogen. The hydrogen is stored and releases in a PEM fuel cell to fulfil the load power demand. Multidomain energy conversion are involved in such a system, the development of a relevant modelling tool is a milestone. It must be able to describe the functional multiphysic aspects which are encountered and respect the macroscopic structure of the conversion system. In fact, both Bond Graph and EMR are obviously suitable to mo- 
del multiphysics systems. However, because of the control aim pursued, EMR is well-adapted here because its description besides the functional and structural features is oriented towards control. Therefore unlike Bond Graph, any derivative relationship is avoided. It has already been used to model multiphysics systems as the energy conversion of a wind generator [12] [13], a variable speed micro hydropower station [14], the modelling and control of fuel cell systems [15] [16] [17] [18] [19] [20].

The different energetic entities will be presented in the logical order of the energetic transfer from the solar energy to the load through the hydrogen storage device. In section 2 , the system architecture is described. In section 3 , the modelling of each component is presented, then the model of the whole system is synthesized. In section 4 , some simulation and some experimental validation are performed.

\section{Overview of the system}

Several researches and developments on the PEM technology have been carried out. The development of this technology for stationary applications is a mid-term objective.

Nevertheless, the exploitation of this chemical converter faces the availability of hydrogen which is the best one to optimize the fuel cell operation. The electrolysis allows a production of hydrogen without $\mathrm{CO} 2$ emissions.

A site isolated from the grid is very common in many countries, particularly in tropical developing countries. Energ requirements have to be fulfilled and the power supply has to be reliable. A system based on the energy vectors as hydrogen and electricity through water electrolysis and fuel cell could be able to play this role. In developed countries where the issue of isolated sites is less critical, it could be a way to manage the balance between production and consumption by producing hydrogen when electricity is too abundant and at low cost and to produce electricity when the demand exceeds the production through a relevant connection to the grid.

In this paper, the first case is considered and the primary source is solar. The synopsis of the power plant is presented figure 1. The energy flow is represented by arrows which direction is consistent with the power exchange. Batteries and/or supercapacities are used as electrical storage depending on the dynamics of the load power, the hydrogen tank as a chemical storage.

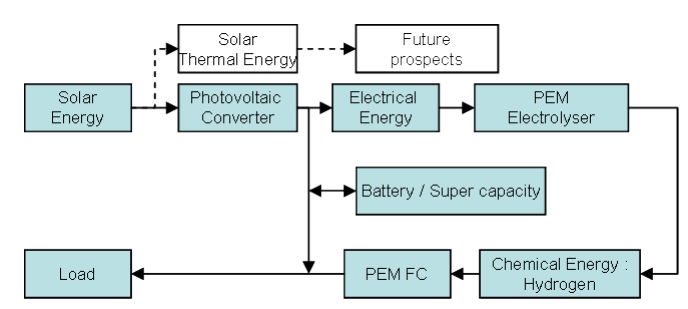

Figure 1. Synoptic scheme of the system

\section{Modelling approach of the system}

The Energetic Macroscopic Representation (EMR) is used as a graphical formalism for the modelling. As Bond Graph, the EMR is able to describe multiphysics complex systems. By inverting the model, a maximal control structure (MCS) can be generated and a practical control structure (PCS) can be deduced taking into account the available measurements from a technical and economical point of view. It has been already applied successfully to several energy systems in different operating conditions [12] [13] [14] [15] [16] [17] [18] [19] [20] [21] [22] [23] [24].

\subsection{Photovoltaic generator model}

EMR is based on the causality principle : a pair of action and reaction variables is defined and their product is a power. In radiometry/photometry, the action/reaction pair is not so obvious. The luminous flux that is received by the solar cell has the dimension of a surfacic power related to the area of the panel. In [25], the energy coming from the sun has been represented by this unique action variable without any reaction variable which is not consistent with the EMR basic principle. In this model, a different approach is proposed where the incident solar energy is taken into account through an action/reaction pair.

For a monochromatic source, a photon flow $D_{P h}$ is emitted : gy

$$
D_{P h}=\frac{d n_{P}}{d t}
$$

Unlike the electric domain where the electronic flow is multiplied by the Faraday constant to obtain the kinetic variable current, the photon flow is multiplied by its granular value (which is an energy) giving directly the power (2).

$$
\phi[W]=E_{P} * D_{P h}=h \nu * \frac{d n_{P}}{d t}
$$

The photon is the elementary energetic entity. The electric state depends on the charge distribution in a given space, by analogy, in radiometry, the distribution of photons on a given surface can be considered as a potential variable. Then the photonic energetic state (for a monochromatic spectrum) on a surface can be assimilated to a potential variable and the photon flow (number of photon per surface and time unity) is the kinetic variable. Then the equation (2) becomes equation (3) :

$$
\phi[W]=A_{\text {kinetic }} * R_{\text {potential }}
$$

Where $R_{\text {potential }}\left[J \mathrm{~m}^{-2}\right]=h \nu * S$

And $A_{\text {kinetic }}\left[s^{-1} m^{-2}\right]=\frac{d n_{P}^{*}}{d t} \quad$ with $\quad n_{P}^{*}=\frac{n_{P}}{S}$

Then equation (4) below can be deduced :

$$
\phi[W]=h \nu * S * \frac{d\left(\frac{n_{P}}{S}\right)}{d t}
$$


This causal approach is consistent with the variable commonly used in radiometry or photometry as the intensity of illuminance $E_{e}\left[W \mathrm{~m}^{-2}\right]$ :

$$
A_{\text {kinetic }}\left[s^{-1} m^{-2}\right]=\frac{E_{e}}{h \nu}\left[s^{-1} m^{-2}\right]
$$

Solar irradiance from canopy of heaven is received on the photovoltaic module area. Part of this energy is absorbed and converted into electrical energy whereas the remaining is released in the module environment as heat. The electrical energy produced is provided to the load through the power electronic component.

The overall EMR of the photovoltaic system is given by figure 2 ; the different component of the model will be explained afterwards.

The photovoltaic conversion leads to thermal exchange between the solar module and the atmosphere that can be described by EMR. In the thermal domain, the pair of action/reaction variables is the pair temperature and entropy flow.

Within the photovoltaic module, three kinds of thermal energy exchanges are occurring firstly, the input heat flow, then the heat flow accumulated in the module and finally the heat dissipation. During the photovoltaic process, the incoming radiation received by module area is not entirely converted into electricity. Therefore, the unconverted energy into electricity constitutes mainly the source of the input heat flow and can be expressed as follows [26] :

$$
\dot{Q}_{i n}=P_{i n}\left(1-\eta_{P V}\right)=A E_{e}\left(1-\eta_{P V}\right)
$$

The resulting entropy flow is $\Delta S_{A t m / P V}=\dot{Q}_{i n} / T_{P V}$. The energy balance by considering input and output heat flows allows presenting the module thermal accumulation like energy storage element as shown in figure 2 and expressed by (equation 7 and 8 ) [26] [27] :

$$
\sum \dot{Q}_{\text {in }}-\sum \dot{Q}_{\text {out }}=C_{P} \frac{d T_{P V}}{d t}
$$

The corresponding equation deduced from equation 7 and involving entropy flow is then given by 8 :

$$
C_{P} \frac{d T_{P V}}{d t}=T_{P V}\left[\sum \Delta S_{\text {in }}-\sum \Delta S_{\text {out }}\right]
$$

In equation (8), $\sum \Delta S_{i n}$ is the sum of the entropic flows of the heat sources and $\sum \Delta S_{\text {out }}$ is the sum of the entropic flows of heat sinks. It can roughly be assumed that $\sum \Delta S_{i n}=\Delta S_{P V / A t m}$ by neglecting both sky and ground radiations according to the suitable assumption that the module temperature is higher than the ambient temperature [26]. As to the sum of heat dissipation entropy flows, it is represented by $\sum \Delta S_{\text {out }}=\Delta S_{A t m / P V}$. Part of solar irradiance absorbed and transformed into electricity is evaluated by electrical variables $V_{p v}$ and $i_{p v}$. A non-linear relationship links the current to the voltage according to equation (9) [26] [28] [29] :

$$
I=I_{p h}-I_{0}\left[\exp \left(\frac{V+I * R_{s}}{n * V_{T}}\right)-1\right]-\frac{V+I * R_{s}}{R_{s h}}
$$

with $V_{T}=\frac{k T_{P V}}{q}$ and $n$ is the junction ideality factor, $k$ the Boltzmann constant, $q$ the charge of the electron. $I_{p h}$ is the photocurrent related to the illuminance by the equation (10) :

$$
I_{p h}=\frac{E_{e}}{E_{e, R E F}}\left(I_{p h, R E F}+\mu_{I S C}\left(T_{P V}-T_{R E F}\right)\right)
$$

The electrical energy from the photovoltaic cell is strongly linked to the solar irradiance. However, because of intermittent meteorological conditions the electrical energy provided is likewise fluctuating. So that, a capacitor is connected to the module to avoid voltage ripple; while current ripple is limited by an inductor. The two accumulation pictograms of the power electronic part of figure 2 and the equations 11,12 below highlight this $C L$ circuit.

$$
\begin{gathered}
i_{p v}-i_{l}=C \frac{d v_{p v}}{d t} \\
v_{p v}-u_{l}=L \frac{d i_{l}}{d t}+r i_{l}
\end{gathered}
$$

In order to provide the maximum power outputted from the solar module to the load, DC converter is subsequently used.

The temperature involved in equation (10) is the module internal temperature. Of course temperature sensors are not implemented in the module and the available temperature is the ambient temperature. Some correlations have been given depending on the operating conditions and the assumptions [30]. Equation (13) [31] is the most generic one and fits the best the considered application :

$$
T_{P V}(C)=0.943 T_{\text {atm }}+0.028 E_{e}-1.528 V_{\text {speed }}+4.3
$$

As already noted, the thermal model is not taken into account in the experimental validation as the module temperature is estimated from the illuminance and the wind speed.

\subsection{PEM Electrolyser model}

The model of the electrolyser is fully described in [32]. As discussed in [32], an electrolyser can be operated by imposing the voltage or the curent depending on the objectives. However it is easier to impose the current to the electrolyser to control the amount of the produced hydrogen. The EMR of the electrolyser is presented in figure 3.

The electric energy supplied to the electrolyser allows on one hand the supply of the free enthalpy of the electrolysis and on the other hand the partial or total supply of the thermal energy needed to activate this endothermal reaction. 


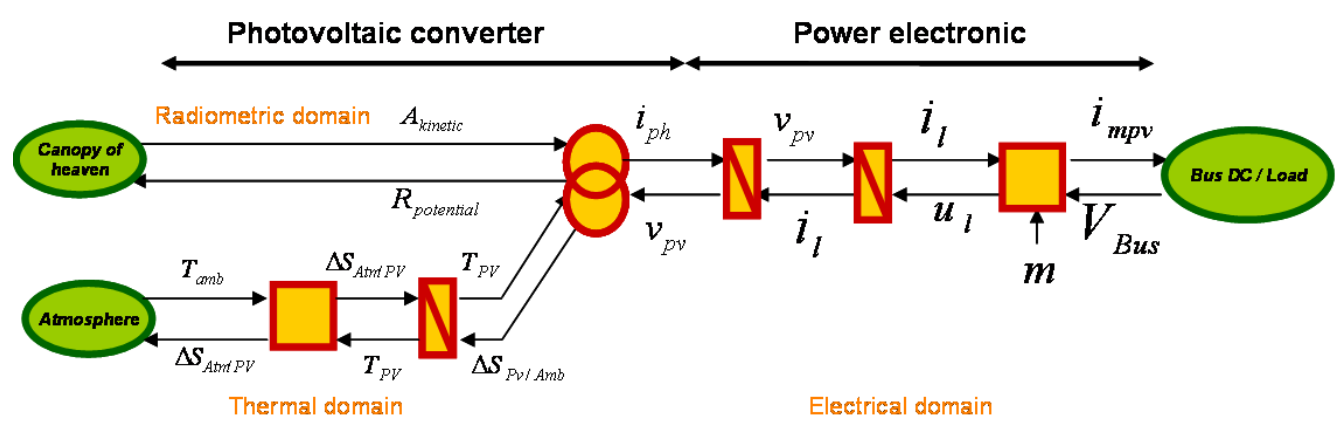

Figure 2. EMR of photovoltaic system

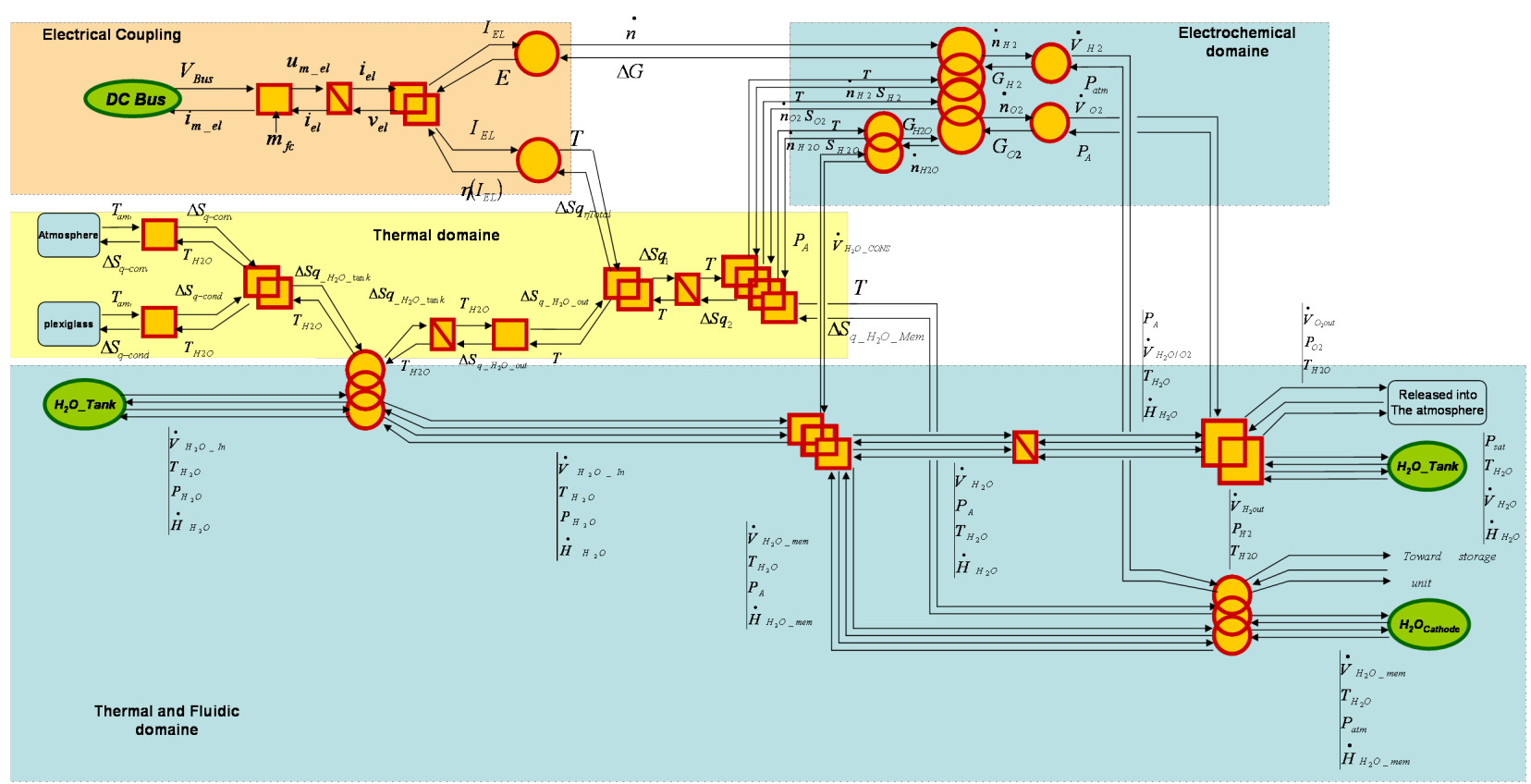

Figure 3. EMR of the PEM electrolyser

\subsection{Storage systems models}

The energy storage is a key point for any sustainable energy system. The instantaneous energy demand and the dynamic of the available energy sources are involved in the sizing of the storage elements. As the considered primary source is intermittent, a storage device is needed to allow both the availability of the energy and the stability of the DC bus. The first function is obtained by the hydrogen storage and the second one is obtained by an electrical storage.

\subsubsection{Hydrogen storage system model}

The hydrogen is produced by the electrolyser and then stored in a tank. Three ways can be considered for the storage : metal hydrid, pressurized and liquid. For stationary applications, storage by metal hydrid and pressurized tanks can be considered [33]. Metal hydrid is expensive from the investment point of view and pressurized storage implies an energy expense for the compression during exploitation [33] [34]. Indeed, the hydrogen is produced at a pressure below 6 bars, it is then compressed and stored at $280 / 350$ bars and finally feeds the PEMFC at around 3 bars ; this cycle spends a high amount of energy and implies a multi stage compression. The right compromise is then to increase the volume of the tank to be able to decrease the storage pressure. The storage chain is presented on the synoptic (Figure 4 ).

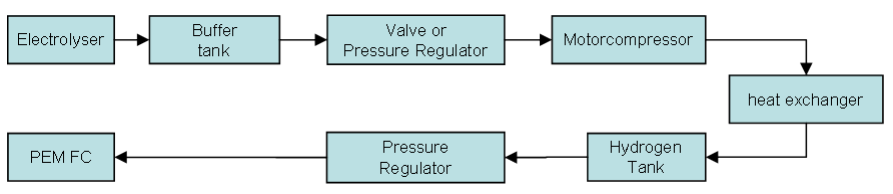

Figure 4. Hydrogen storage system

The fuel cell operating pressure is checked by the pressure regulator located downstream the hydrogen tank. Furthermore, the compressor (compression) and the pres- 
sure regulator (volumic expansion) inlet and outlet temperatures are managed by an isentropic process. Thus, by using a pressure regulator upstream the compressor, the outlet temperature will be relatively lower and the exchanger could be avoided. However, the exchanger would be used if the upstream pressure regulator is omitted.

\subsubsection{Buffer tank}

The gas supplied by the electrolyser is stored in a buffer tank to avoid the compression operation at too low load or without load. In order to control the hydrogen temperature for security reasons, thermo-pneumatic variables are used to describe the conversion chain (appendix). The hydrogen mass flow of the stored hydrogen $\dot{m}_{B T}$ is the buffer inlet mass flow $\left(\dot{m}_{e l}\right)$ minus the outlet mass flow $\left(\dot{m}_{B T-\text { out }}\right)(14)[35]$ :

$$
\dot{m}_{B T}(\tau)=\dot{m}_{e l}-\dot{m}_{B T-\text { out }}
$$

The hydrogen mass in the buffer is :

$$
\dot{m}_{B T}\left(t_{0}+\Delta t\right)=\int_{0}^{t_{0}+\Delta t} \dot{m}_{B T}(\tau) d(\tau)+\dot{m}_{B T}\left(t_{0}\right)
$$

The buffer pressure is obtained by the perfect gas law :

$$
P_{B T}=\frac{R T_{B T}}{V_{r e s-B T}} m_{B T}
$$

With $V_{\text {res-BT }}$ the buffer volume.

The EMR component of this unit is quoted thereafter as "buffer tank" onto the overall hydrogen storage system EMR model figure (Figure 6).

\subsubsection{Pressure regulator}

The physical causality of the pressure controller is described in figure 5 . The pressure controller model developed in [36] has been used. An isentropic process is assumed to describe the thermodynamical parameters in each body of the controller. The inlet and outlet variables (pressure, mass flow) are tuned by adjusting mechanical parameters according to the stability study in [36]. It can be found on the overall model as the "Pressure regulator" block (figure $6)$.

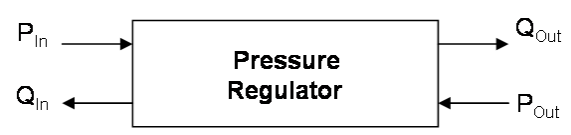

FIGURE 5. pressure regulator causality

\subsubsection{Moto -compressor}

In [37] [38], the EMR of a air moto-compressor group has been developed considering a DC current machine for the electrical motor. However for security reasons, sparkles should be avoided in a hydrogen compressor so a permanent magnet synchronous machine is preferred. In [22] the EMR modelling of a synchronous machine has been presented, in [39] a permanent magnet synchronous machine is developed and its practical control structure as well. The last is based on equations in [13] and [39]. It has been chosen to use the same model and the same control law in this study. The detailed EMR model is given in [37] [38] for the pneumatic domain.

The thermal domain is added in this study. An isentropic process is assumed leading to the equations (17-19) [40] [41] [37] [38]. According to figure 6, this submodel can be recognized as "permanent magnet synchronous motor" and "one stage compressor".

$$
T_{\text {out }}=T_{\text {in }}\left(\frac{P_{\text {out }}}{P_{\text {in }}}\right)^{\frac{k-1}{k}}
$$

$$
\begin{gathered}
T_{\text {comp }}=\frac{P_{\text {mec }}}{\Omega_{\text {shaft }}} \dot{m}_{\text {in }} C_{P} T_{\text {in }}\left(\left(\frac{P_{\text {out }}}{P_{\text {in }}}\right)^{\frac{k-1}{k}}-1\right) \\
P_{M e c}=\frac{1}{\eta_{\text {adi }} \eta_{M e c}}
\end{gathered}
$$

$$
\begin{array}{ll}
P_{M e c} & \text { Mechanical power of the compressor } \\
\eta_{a d i} & \text { Adiabatic efficiency of the compressor head } \\
\eta_{M e c} & \text { Mechanical efficiency of the compressor head } \\
C_{P} & \text { Thermal capacity of the hydrogen } \\
\gamma & \text { Adiabatic compression coefficient }
\end{array}
$$

As it can be seen given to this EMR unit, an exchanger can be introduced between the pressure regulator and the tank.

\subsubsection{Heat exchanger}

A counterflow heat exchanger is considered. Water is used as coolant which permits to control hydrogen temperature if it is necessary considering the tanks capacities and the compression dynamic.

$q_{t}=q_{m} C_{P}$ is the heat capacity flow-rate where $q_{m}$ is the mass flow-rate and $C_{P}$ the specific heat capacity. $q_{t-h o t}$ is the heat capacity flow-rate of the hot fluid and $q_{t-\text { cold }}$ is the heat capacity flow-rate of the cold fluid.

The maximum heat flow which can be transferred from the hot fluid to the cold fluid is [42] :

$$
\phi_{\max }=\min \left(q_{t-h o t} ; q_{t-c o l d}\right)\left(T_{h o t-i n}-T_{c o l d-i n}\right)
$$

$\min \left(q_{t-h o t} ; q_{t-\text { cold }}\right)$ is the smallest heat capacity flow-rate 
between the hot fluid and the cold fluid.

The real thermal power (or heat flow) exchanged is expressed in equation (21) :

$$
\phi=E \phi_{\max }
$$

Where the thermal effectiveness $E$ is linked by the number of transfer unit $(N T U)$ and the ratio $R$ (the ratio between minimum and maximum of heat capacity flowrate considering both the hot fluid and the cold fluid) according to equation (22) [42] :

$$
E=\frac{1-\exp [-(1-R) N U T]}{1-\operatorname{Rexp}[-(1-R) N U T]}
$$

With $R=\frac{\min \left(q_{t-h o t} ; q_{t-c o l d}\right)}{\max \left(q_{t-h o t} ; q_{t-\text { cold }}\right)}$ and

$$
N U T=\frac{k \Sigma}{\min \left(q_{t-h o t} ; q_{t-c o l d}\right)}=\frac{K}{\min \left(q_{t-h o t} ; q_{t-c o l d}\right)}
$$

Moreover, the outlet temperatures of the hot and the cold fluids can be expressed as in (24-25) [42].

$$
\begin{gathered}
T_{\text {hot-out }}=T_{\text {hot-in }}-\frac{\phi}{q_{t-h o t}} \\
T_{\text {cold-out }}=T_{\text {cold-in }}-\frac{\phi}{q_{t-\text { cold }}}
\end{gathered}
$$

Where $T_{\text {hot-in }}$ and $T_{\text {cold-in }}$ are respectively the inlet temperatures of the hot and the cold fluids.

The thermo-pneumatical causality uses four parameters (appendix) because of liquid fluid is used as coolant [15] [32]

\subsubsection{Storage tank}

The modelling approach is the same than the buffer tank model and can be located onto the EMR of the figure 6 under the name "Tank".

\subsubsection{EMR of hydrogen storage system}

According to each component of the figure 4, the EMR model of the hydrogen storage system is presented (Figure 6).

\subsubsection{Electrical energy storage system model}

The considered electrical energy storage devices are the battery and the supercapacitor pack. According to the energy requirement, both can be used, the battery as an energy source to fulfil the energy availability constraints and supply during the long transients of the other sources and the supercapacitor as a power source during motor start-up for instance.

\subsubsection{Battery}

The battery is expected to assume partly the energy storage in order to answer to a potential lack of energy caused by the electrical generator.

Between the several battery technologies, the lead-acid batteries are commonly used for stationary application as the mass and weight constraints are low. A third-order model with 3 state variables (current, temperature and electrical charge) [43] [44] has been chosen (figure 7).

\subsubsection{Supercapacitor pack}

The supercapacitor is expected to assume the power storage in order to manage the power peak in the start-up phase.

The supercapacitor is based on the model of Zubieta [45]. The supercapacitor as described in several EMR model [23] [37] [38] [43] [46] uses current as action variable and voltage as reaction variable. These electrical parameters are linked according to equation (26) below :

$$
V_{\text {scaps }}=R_{i} i_{\text {scaps }}+\frac{1}{C_{0}+2|K| V} \int i_{\text {scaps }} d t
$$

The losses into the capacity device are modelled by the internal serial resistance $R_{i}$ which expresses the thermal dependency according to equation (27) [37]. This phenomenon implies power dissipation as heat $\left(P_{\text {loss }}\right)$; hence the resulting coupling pictogram leads to the thermal domain as shown in figure 8 . Through the power electronic, the supercapacitor electrical field is connected to the DC Bus.

$$
R_{i}=R_{20} \frac{1+\exp \left(-k_{T}\left(T_{\text {scaps }}-T_{20}\right)\right)}{2}
$$

\subsection{PEM fuel Cell model [37] [43] [47]}

Hydrogen and oxygen are provided respectively at both the anode and the cathode. Fluidic motions (fluidic domain) occur and the gas arrive at the electrode membrane assemblies interfaces. At the cathode and the anode sides, exothermic electrochemical reactions allow producing water and electricity (electrical, electrochemical and thermal coupling). The load (DC Bus) through the power electronic component is supplied by the produced electrical energy. The fuel cell system (FCS) including the stack and the mains ancillaries is presented in figure 9 [37] [43] [47].

\subsection{Whole system}

The whole power generator of the local grid is presented (figures 10 and 11). 


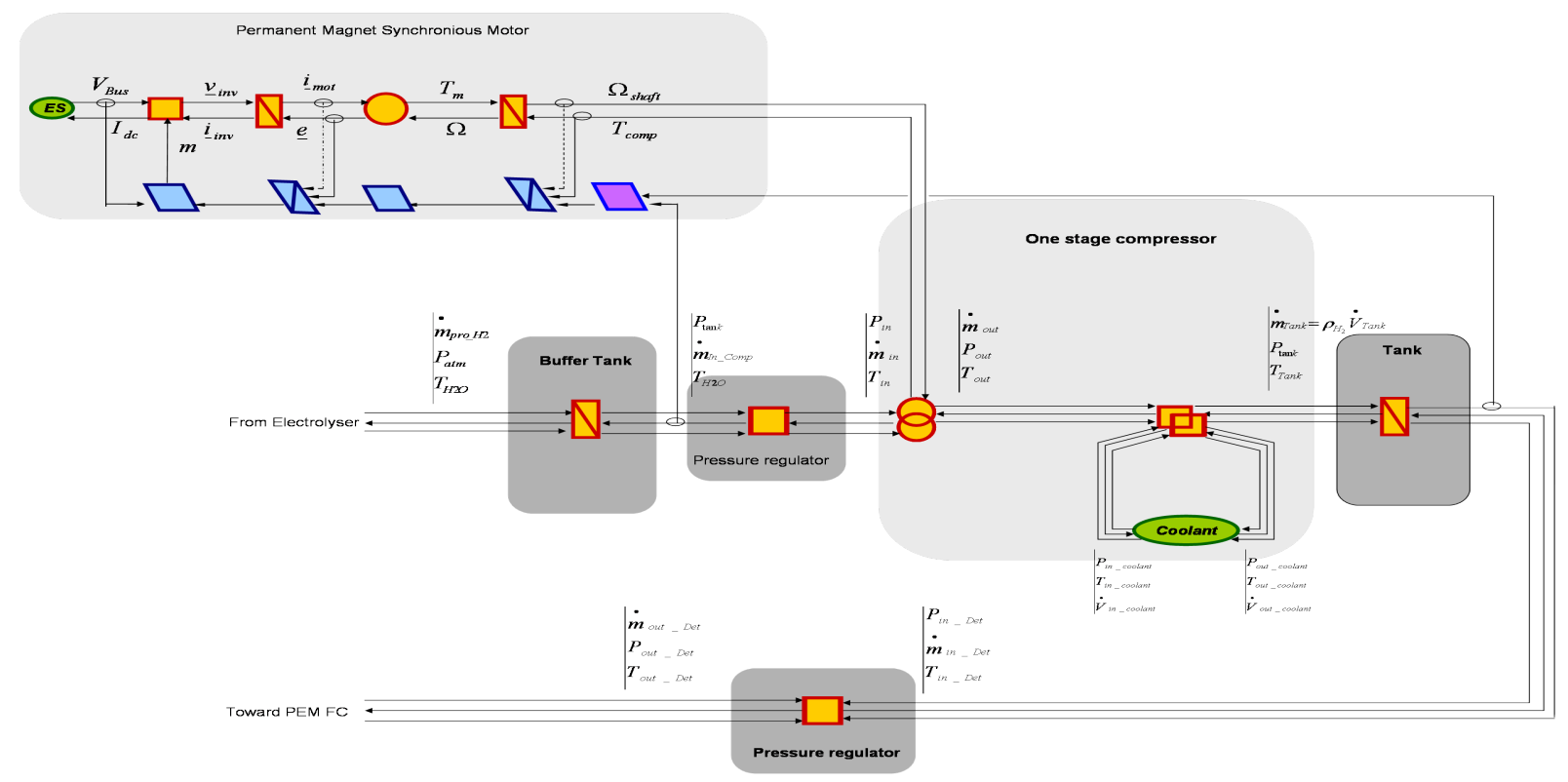

FIGURE 6. EMR of hydrogen tank charge/discharge process
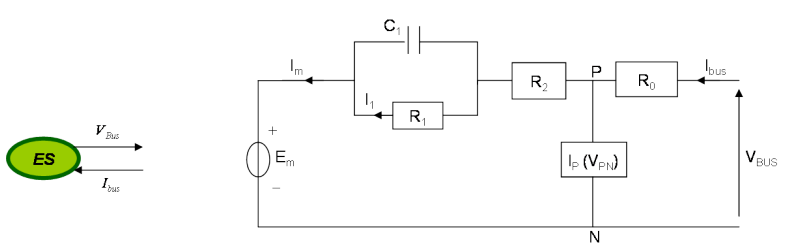

FIGURE 7. Battery EMR and equivalent circuit

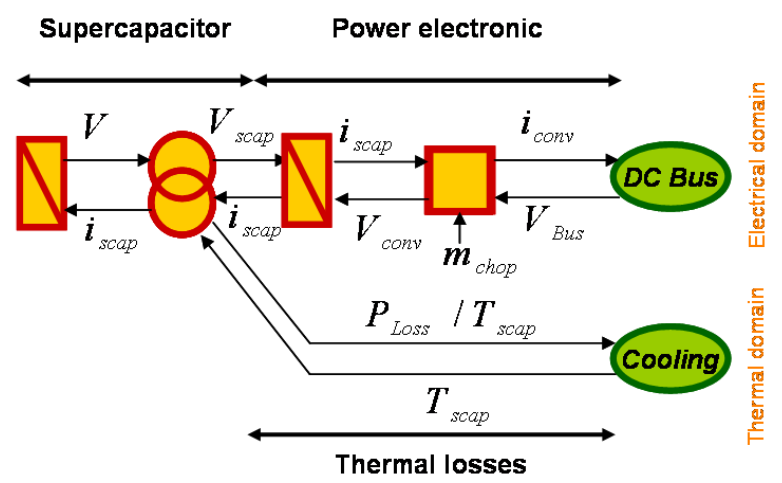

Figure 8. SCAP system EMR

\section{Experimental and/or simulation Results of each device of the system}

As a first validation step, main component models described in the previous section have been validated experimentally and the results are presented in this section. For the others, only simulation results are reported.

\subsection{Photovoltaic generator}

The detailed thermal model has been described but the tuning of the variables from experiments has not been achieved. The correlation of the equation (10) is preferred and gives an estimation of the module temperature. The average wind speed is taken from the wheather data of the experimental site (East of France, Belfort). The electrical model is validated thanks to experiments on a TE 850 TOTAL ENERGIE of $90 \mathrm{WP}$. The parameters have been tuned according to the method used in [48] [49] (figure 12). 


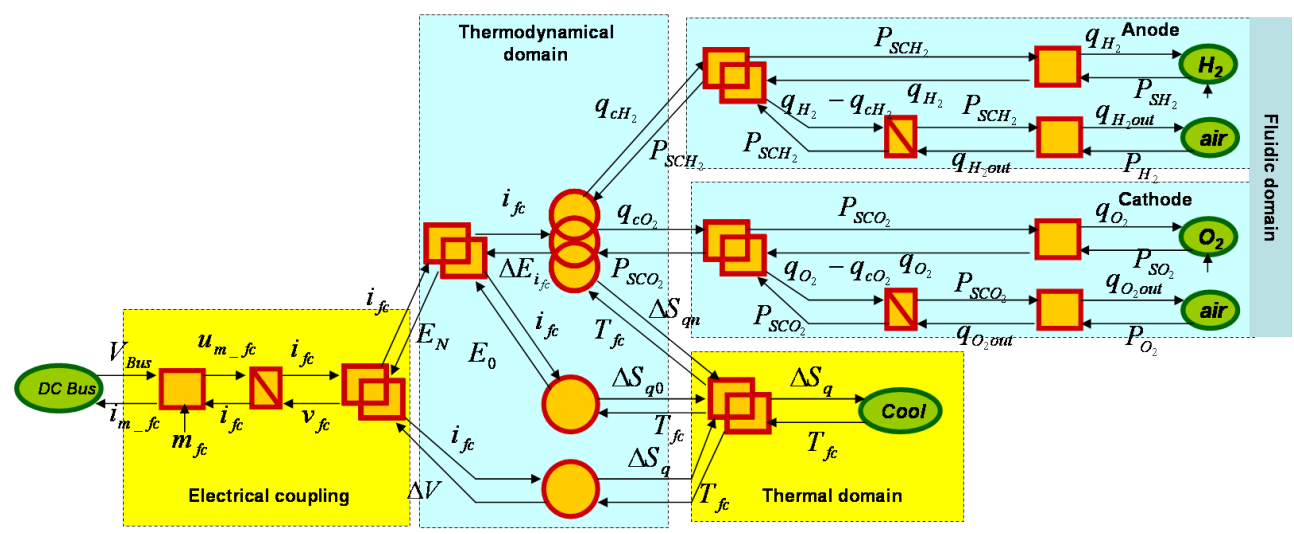

Figure 9. EMR of PEM FCS

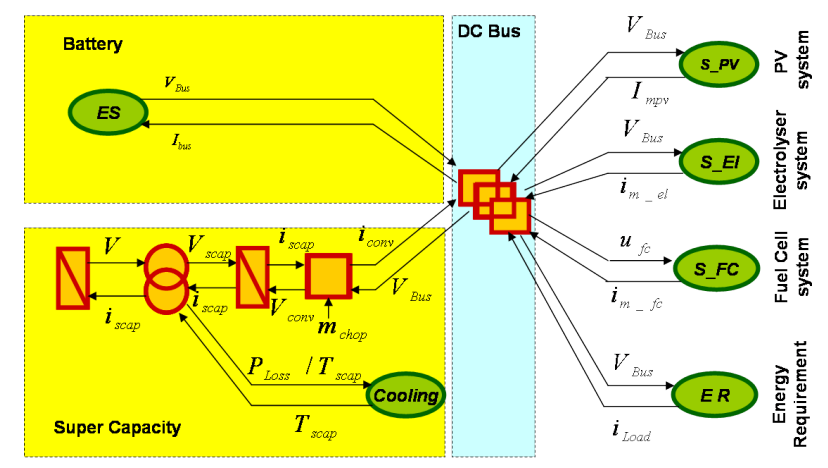

Figure 10. EMR synoptic of the stationary system

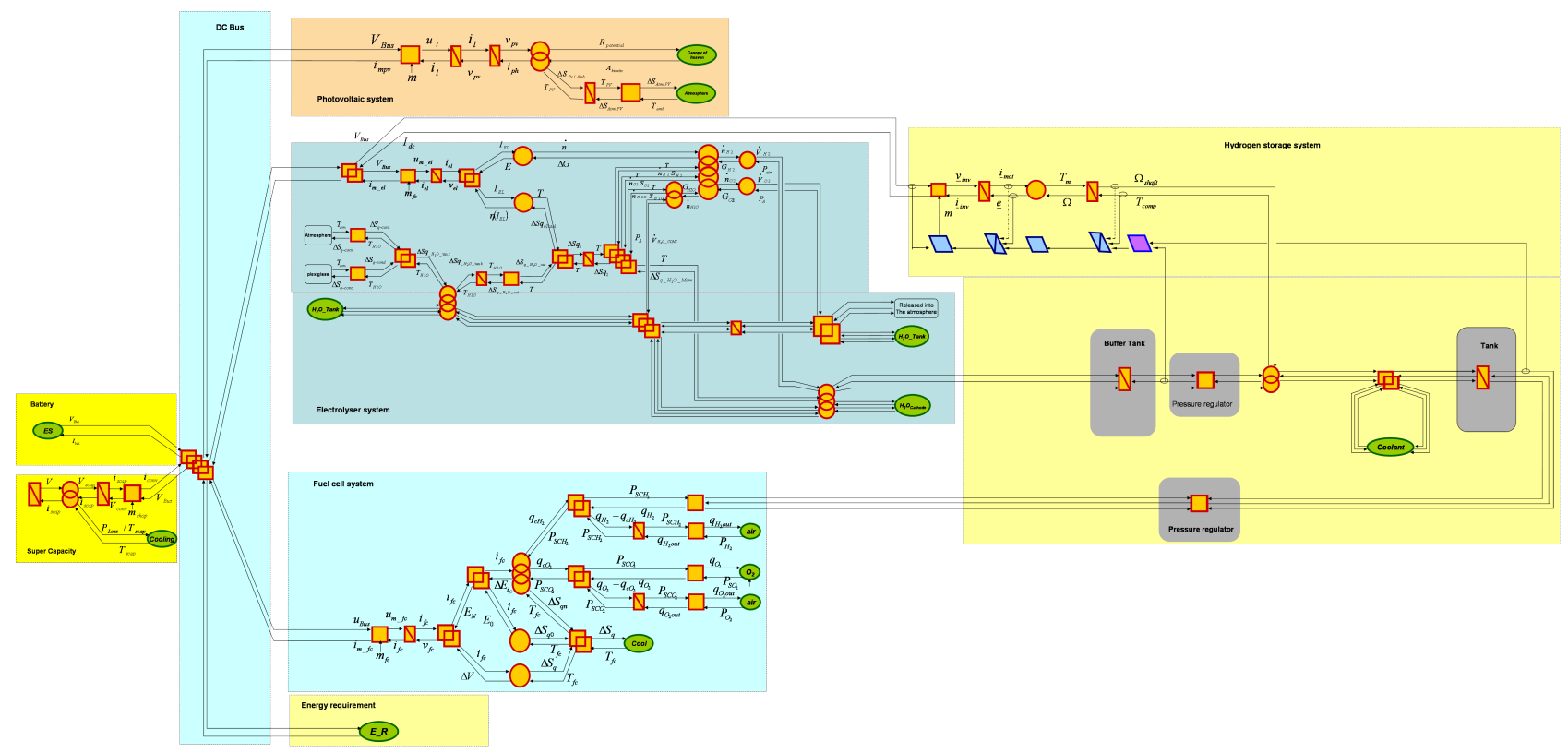

FIGURE 11. EMR of the stationary system 


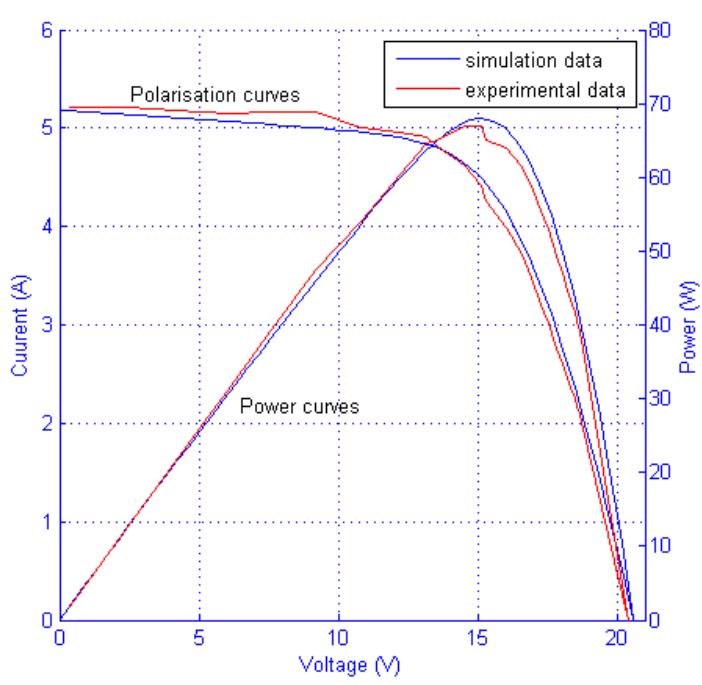

Figure 12. Photovoltaic model results

\subsection{PEM electrolyser [32]}

According to those parameters below obtained by the curve fitting method, the electrolyser model has been validated and the results are shown in figures $(13,14,15$, and 16) :

$$
\begin{aligned}
& j_{0 . A}\left(A \mathrm{~cm}^{-2}\right)=0.1548 * 10^{-2} \\
& j_{0 . C}\left(A \mathrm{~cm}^{-2}\right)=0.3539 * 10^{-1} \\
& \sigma(S / \mathrm{cm})=0.9322 * 10^{-2} \\
& \alpha_{A}=0.7178 \\
& \alpha_{C}=0.6395
\end{aligned}
$$

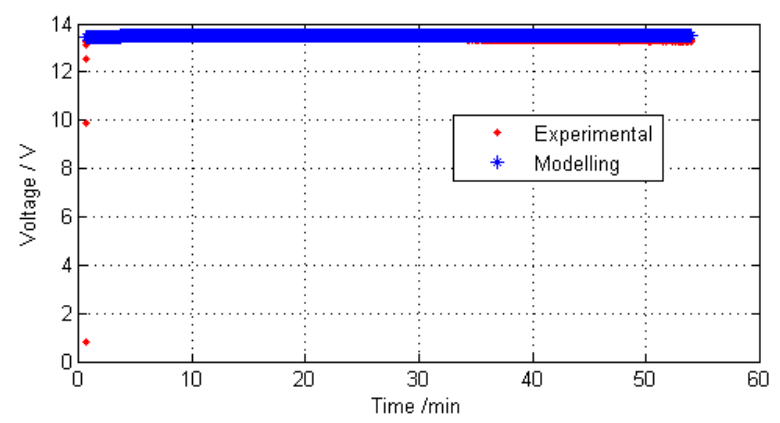

Figure 13. Voltage response to the current step 4A

\subsection{PEM Fuel Cell}

The PEM FC model has already been validated experimentally [43] [47] [50]. The polarization curve is performed for 20 cells stack with $100 \mathrm{~cm}^{2}$ area (figures (17)).

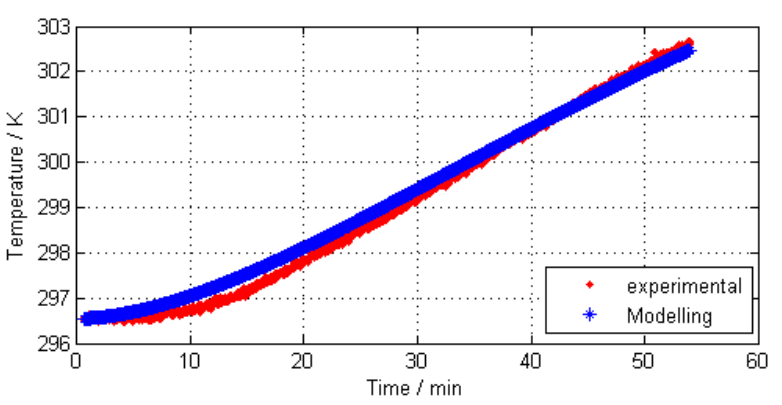

Figure 14. water tank temperature profile

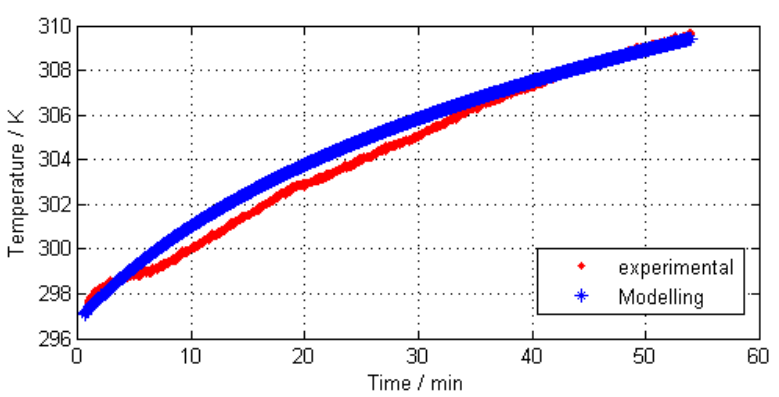

FIGURE 15. Stack temperature profile

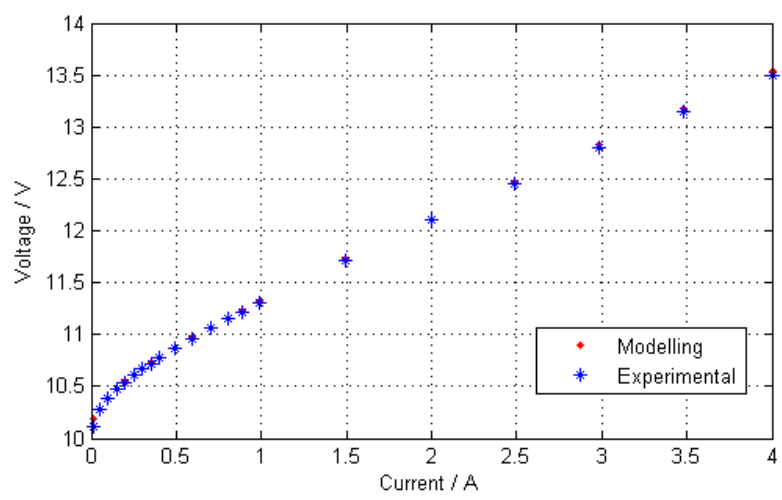

Figure 16. Electrical curves

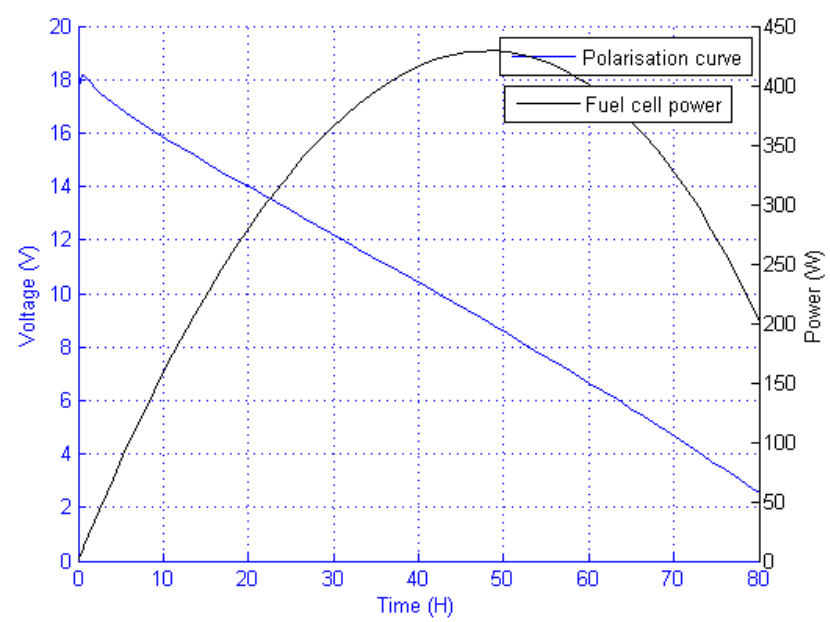

Figure 17. Fuel cell power 


\subsection{Hydrogen Storage system}

In the presented results, the pressure regulator is assumed to be ideal so the pressure at the compressor inlet is fixed at $1 \mathrm{~atm}$. In the simulation (Figures 18, 19), a current step is applied to the electrolyser during 5 hours. The pressure in the buffer tank increases and reaches around $1.5 \mathrm{~atm}$ and it increases slowly as well in the main tank with the increase of the pressure ratio. When the current is shut down, the buffer empties and its pressure decreases. The pressure in the main tank keeps increasing until the buffer pressure reaches the atmospheric pressure.
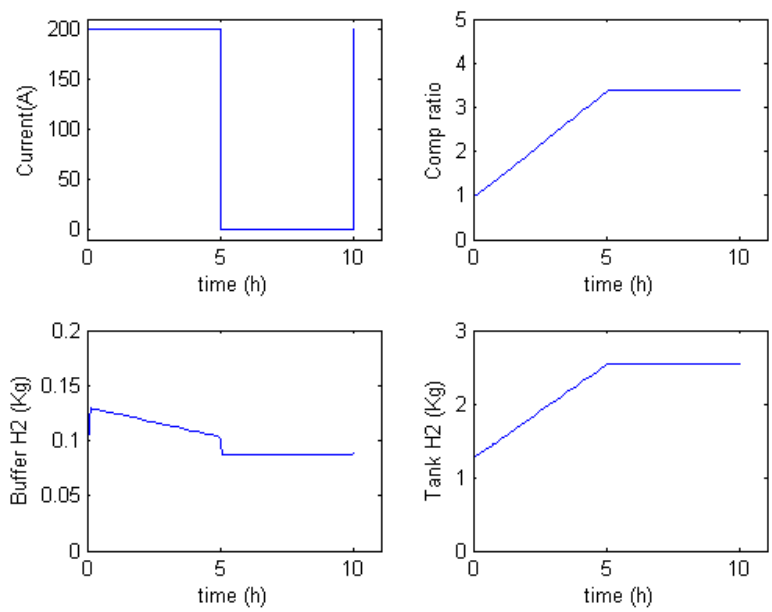

Figure 18. Hydrogen storage chain : Current set point, compression ratio, hydrogen height in the buffer and in the tank

\subsection{Pressure regulator stability}

As it is noticed above, the pressure regulator of [36] is used. It can be tuned on any operating point by adjusting the mechanical set point. Figure 20 below highlights the pressure regulator stability. The stabilisation depend on the gas flow area handled by external set-point imposing the behaviour pressure.

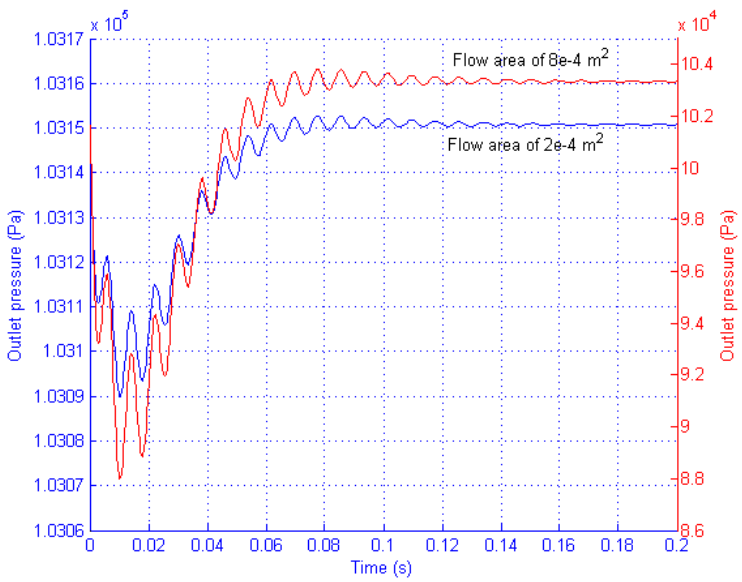

FIGURE 20. Pressure regulator stability

\section{Conclusion and perspectives}
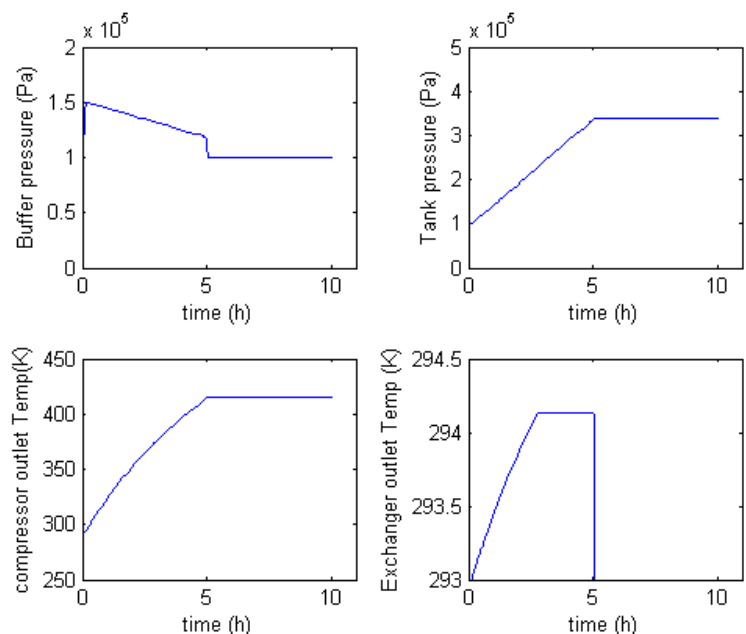

Figure 19. Hydrogen storage chain : Buffer pressure, tank pressure, compressor outlet temperature, exchanger outlet temperature

In order to model an overall energetic system, the modularity of the EMR formalism is helpful allowing the modelling of the system entity by entity. As REM is developed with respect to physical causality, it is then possible by simple arrangement of the different entities to reconstruct the model's overall energy device. Furthermore, there is a proportionality relationship between the electrical characteristics of electrolyser's cell and stack, and between a photovoltaic cell and module, panel or photovoltaic field. Therefore, due to the scale effect, the modelling of the entire chain of energy storage process was done.

Using this model, extensible by its granularity, it is possible to simulate a control or an energy optimization of energetic devices. The experimental validation of a complete system can be envisaged for validation. Given to several purposes namely the prediction, the control, and the energetic optimisation, one can use a multiphysics modelling approach to model an energy production system of stationary application using the EMR graphical modelling tool thanks to its structural and functional characteristics. 


\begin{tabular}{|c|c|c|c|c|c|}
\hline & Source of energy & & 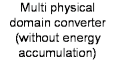 & & $\begin{array}{c}\text { Control block } \\
\text { without } \\
\text { controller }\end{array}$ \\
\hline & 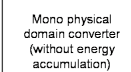 & $=\Delta=$ & $\begin{array}{l}\text { Element with } \\
\text { aceneryulation }\end{array}$ & $\nabla$ & $\begin{array}{l}\text { Controlloloke } \\
\text { with ontrolere }\end{array}$ \\
\hline & 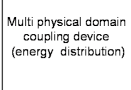 & $\vec{c}$ & 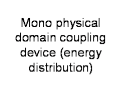 & & $\begin{array}{l}\text { Thermo-pneumatic } \\
\text { causality } \\
\text { (four variables for } \\
\text { liquid and thee } \\
\text { variables for gas) }\end{array}$ \\
\hline
\end{tabular}

FiguRE 21. EMR pictograms

\begin{tabular}{ll}
\hline Nomenclature & \\
\hline Symbols & Symbols meaning \\
$n_{p}$ & Number of protons \\
$h[J s]$ & Planck constant $\left(6,626 e^{-34}\right)$ \\
$\nu$ & Frequency \\
$S$ & Surface crossed by the photons \\
$R_{s}[\Omega]$ & Module serie resitance \\
$R_{s h}[\Omega]$ & Module shunt resitance \\
$E_{e}\left[W m^{2}\right]$ & Irradiance \\
$E_{e, R E F}\left[W m^{2}\right]$ & reference irradiance (1000) \\
$V_{s p e e d}\left[\mathrm{~ms}^{-1}\right]$ & Wind speed \\
$P_{i n}[W]$ & Power received By the module \\
$\eta_{P V}$ & Efficiency \\
$T_{P V}$ & Module temperature \\
$C_{P}\left[J K^{-1}\right]$ & Module heat capacitance \\
\hline
\end{tabular}

\section{Références}

1. E.A. Katz, S. Gevorgyan, M.S. Orynbayev, F.C. Krebs. Eur. Phys. J. Appl. Phys. 363 (2006) 307-311

2. B. Minnaert, M. Burgelman. Eur. Phys. J. Appl. Phys. 38 2 (2007) 111-114

3. N. Meyer, M. Rusu, S. Wiesner, S. Hartmann, D. Keiper, M. Schwambera, M. Gersdorff, M. Kunat, M. Heuken, W. Kowalsky and M.Ch. Lux-Steiner. Eur. Phys. J. Appl. Phys. 461 (2009) 12506

4. A.M.A. El-Barry. Eur. Phys. J. Appl. Phys. 403 (2007) 241-246

5. K.F. Abd El-Rahman. Eur. Phys. J. Appl. Phys. 372 (2007) 143-147.

6. J. Rodriguez, D. Bruneau, A. Guiavarch, C. Gobbé. Eur. Phys. J. Appl. Phys. 401 (2007) 95-112.

7. J. Hanisch, E. Ahlswede, M. Powalla. Eur. Phys. J. Appl. Phys. 373 (2007) 261-264.

8. A. Bouzidi, A.S. Bouazzi, B. Rezig. Eur. Phys. J. Appl. Phys. 311 (2005) 11-16.

9. S. Nara, T. Sekiguchi, J. Chen. Eur. Phys. J. Appl. Phys. 27 1-3 (2004) 389-392

10. P. Brault, S. Roualdès, A. Caillard, A.-L. Thomann, J. Mathias, J. Durand, C. Coutanceau, J.-M. Léger, C. Charles, R. Boswell. Eur. Phys. J. Appl. Phys. 342 (2006) 151-156

11. P. Brault, S. Roualdès, A. Caillard, A.-L. Thomann, J. Mathias, J. Durand, C. Coutanceau, J.-M. Léger, C. Charles, R. Boswell. Eur. Phys. J. Appl. Phys. 431 (2008) 137
12. Ph. Delarue, A. Bouscayrol, A. Tounzi, X. Guillaud, G. Lancigu. Renewable Energy 28 (2003) 1169-1185.

13. A. Bouscayrol, Ph. Delarue, X. Guillaud. Renewable Energy 30 (2005) 2273-2288.

14. A. Ansel, B. Robyns. Mathematics and Computers in Simulation 71 (2006) 320-332.

15. D. Chrenko, J. Coulié, S. Lecoq, M.C. Péra, D. Hissel. International Journal of Hydrogen Energy. 34 (2009)1324-35.

16. D. CHRENKO. Ph.D thesis, University of Franche-Comte, 25 November 2008.

17. D. Chrenko, M.C Péra, D. Hissel, A. Bouscayrol. Journal of Fuel Cell Science and Technology, Trans. of the ASME. 6 (05-2009) 024501-1/5.

18. D Chrenko, M-C Pera, D Hissel. Power Electronics and Motion Control Conference, 2008. EPE-PEMC 2008, 13th,Poznan-Poland.

19. D Chrenko, M-C Pera, D Hissel. Industrial Electronics, 2007. ISIE 2007. IEEE International Symposium, 2007, Pages 169-174,Vigo-Spain.

20. L Boulon, D Hissel, A Bouscayrol, M-C Pera. Industrial Electronics, IEEE Transactions on Volume : 57, Issue : 6, 2010, Page(s) : 1882-1891, Bari-italy.

21. T. Zhou. Ph. D from the Ecole Centrale of Lille, 30 June 2009.

22. E. Semail, A. Bouscayrol, J-P. Hautier. Eur. Phys. J. AP 223 (2003) 207-220.

23. Y. Haifang, L. Rengui, W. Tiecheng, Z. Chunbo. Vehicle Power and Propulsion Conference, 2009. VPPC '09. IEEE, Pages : 1390-1394, Dearborn-USA.

24. T. Bossmann, A. Bouscayrol, P. Barrade, S. Lemoufouet, A. Rufer. Industrial Electronics, 2007. ISIE 2007. IEEE International Symposium on. Pages : 2691-2696, Vigo-Spain.

25. Y. Pankov. Ph.D thesis, Ecole Supérieure d'Arts et metiers, 10 december 2004.[In French]

26. S. Krauter Solar Electric Power Generation. (Springer, Berlin Heidelberg, 2006)

27. R García-Valverde, C Miguela, R Martínez-Béjar, A Urbina. Int J Hydrogen Energy.2008;33:5352-62.

28. T Tafticht, K Agbossou, M.L Doumbia, A. Chériti. Renewable Energy, 2008; 33 : 1508-16.

29. J Enrique, E Durán, M Sidrach-de-Cardona, J. M Andújar. Solar Energy, $2007 ; 81: 31-38$.

30. E. Skoplaki, J.A. Palyvos. Renewable Energy. 34 (2009) 23-29.

31. R. Chenni, M. Makhlouf, T. Kerbache, A. Bouzid. Energy. 32 (2007) 1724-30.

32. K. S. Agbli, D. Hissel, M. C. Péra, O. Rallières, C. Turpin, I. Doumbia. Multiphysics simulation of a PEM electrolyser : Energetic Macroscopic Representation approach. Int. Journal of Hydrogen Energy (2010) [In press].

33. E. López, F. Isorna, F. Rosa. International Journal of Hydrogen Energy. 32 (2007) 1537-41.

34. F. Posso, A. Contreras, A. Veziroglu. Renewable Energy. 2009 ; 34 :1234-40.

35. T. Zhou, B. François. International Journal of Hydrogen Energy. 341 (2009) 21-30. 
36. N. Zafer, G. R. Luecke. Applied Mathematical Modelling. $32 ; 2008: 61-82$.

37. L. Boulon, M-C. Péra, P. Delarue, A. Bouscayrol, D. Hissel. Journal of Fuel Cell Science and Technology, 12-2009.

38. L. Boulon, D. Hissel, A. Bouscayrol, M-C. Pera, P. Delarue. Vehicle Power and Propulsion Conference, 2008. VPPC '08. IEEE. Page(s) : 1-6, Harbin-china.

39. J. Solano-Martínez, D. Hissel, M-C. Péra, M. Amiet. In proc. of IEEE-VPPC'10, France, 2010, to be published, LilleFrance.

40. A. Lallemand. Technique de l'Ingénieur. 10 April 2003; BE 8 013, 26 Pages [in French].

41. J-M. Merigoux. Technique de l'Ingénieur 10 July. 1999 ; BM 4 500, 36 pages [in French].

42. A. Bontemps, A. Garrigue, C. Goubier, J. Huetz, C. Marvillet, P. Mercier, R. Vidil. Technique de l'Ingénieur. $10 \mathrm{Fe}-$ bruary. 1994; B 2 340, 20 pages [in French]

43. J. Solano-Martínez, L. Boulon; D. Hissel ; M-C. Péra; M. Amiet. 5th IEEE Vehicle Power and Propulsion Conference, VPPC '09, 2009, pages 1322-1329, Dearborn-USA.

44. M. Ceraolo. IEEE Transactions on Power Systems, Volume 15, Issue 4, Nov 2000 Page(s) :1184 - 1190.

45. L Zubieta, R Bonert. Industry Applications, IEEE Transactions on; volume 36, (1) 2000, Page(s) : 199-205.

46. L. Boulon, M-C. Pera, D. Hissel, A. Bouscayrol, P. Delarue. Vehicle Power and Propulsion Conference, 2007. VPPC 2007. IEEE. Pages : 290-297, Arlington-USA.

47. D. Hissel, M-C. Péra, A. Bouscayrol, D. Chrenko. Revue internationale de génie électrique vol 11, pp. 603-623 , 2008 [in French].

48. D. Brunelli, D. Dondi, A. Bertacchini, L. Larcher, P. Pavanc, L. Benini. Microelectronics Journal, 2009 ; 40 : 1337-44.

49. D. Dondi, D. Brunelli, L. Benini, P. Pavan, A. Bertacchini, L. Larcher. in : Proceedings of the Second International Workshop on Advances in Sensors and Interface, IWASI 2007, Bari, Italy, 2007. Pages 1-6.

50. L. Boulon. Ph.D thesis, University of Franche-Comté, 03 July 2009 [in French]. 